\title{
The paradoxical psychological effects of lysergic acid diethylamide (LSD)
}

\author{
R. L. Carhart-Harris ${ }^{1 *}$, M. Kaelen ${ }^{1}$, M. Bolstridge ${ }^{1}$, T. M. Williams ${ }^{2}$, L. T. Williams ${ }^{1}$, R. Underwood ${ }^{3}$, \\ A. Feilding ${ }^{4}$ and D. J. Nutt ${ }^{1}$ \\ ${ }^{1}$ Imperial College London, Centre for Neuropsychopharmacology, Division of Brain Sciences, Faculty of Medicine, London, UK \\ ${ }^{2}$ Department of Psychiatry, The University of Bristol, Bristol, UK \\ ${ }^{3}$ Institute of Psychiatry, Psychology \& Neuroscience, Department of Psychology, King's College London, London, UK \\ ${ }^{4}$ The Beckley Foundation, Beckley Park, Oxford, UK
}

Background. Lysergic acid diethylamide (LSD) is a potent serotonergic hallucinogen or psychedelic that modulates consciousness in a marked and novel way. This study sought to examine the acute and mid-term psychological effects of LSD in a controlled study.

\begin{abstract}
Method. A total of 20 healthy volunteers participated in this within-subjects study. Participants received LSD (75 $\mu \mathrm{g}$, intravenously) on one occasion and placebo (saline, intravenously) on another, in a balanced order, with at least 2 weeks separating sessions. Acute subjective effects were measured using the Altered States of Consciousness questionnaire and the Psychotomimetic States Inventory (PSI). A measure of optimism (the Revised Life Orientation Test), the Revised NEO Personality Inventory, and the Peter's Delusions Inventory were issued at baseline and 2 weeks after each session.
\end{abstract}

Results. LSD produced robust psychological effects; including heightened mood but also high scores on the PSI, an index of psychosis-like symptoms. Increased optimism and trait openness were observed 2 weeks after LSD (and not placebo) and there were no changes in delusional thinking.

Conclusions. The present findings reinforce the view that psychedelics elicit psychosis-like symptoms acutely yet improve psychological wellbeing in the mid to long term. It is proposed that acute alterations in mood are secondary to a more fundamental modulation in the quality of cognition, and that increased cognitive flexibility subsequent to serotonin $2 \mathrm{~A}$ receptor $\left(5-\mathrm{HT}_{2 \mathrm{~A}} \mathrm{R}\right)$ stimulation promotes emotional lability during intoxication and leaves a residue of 'loosened cognition' in the mid to long term that is conducive to improved psychological wellbeing.

Received 11 August 2015; Revised 2 December 2015; Accepted 2 December 2015; First published online 5 February 2016

Key words: LSD, mood, psychedelics, psychosis, serotonin.

\section{Introduction}

Lysergic acid diethylamide (LSD) is a potent serotonergic hallucinogen or 'psychedelic' that alters consciousness in a marked and unusual way. The drug was first intentionally consumed by the Swiss chemist Albert Hofmann in 1943 in a self-experiment in which he ingested $250 \mu \mathrm{g}$ (a high dose) in his laboratory before travelling home. In a detailed report of his experience, written a few days later, Hofmann describes an initially unpleasant experience, characterized by altered perception, fear and paranoia: his next-door neighbour transformed into a 'malevolent, insidious witch with a coloured mask', he sensed a 'disintegration of the outer

\footnotetext{
* Address for correspondence: R. L. Carhart-Harris, Imperial College London, Centre for Neuropsychopharmacology, Division of Brain Sciences, Faculty of Medicine, London, UK.

(Email: r.carhart-harris@imperial.ac.uk)
}

world', a 'dissolution of [his] ego' and was 'seized by a dreadful fear of going insane' (Hofmann, 1980).

From this account, it would be reasonable to suspect that Dr Hofmann was negatively affected by this experience but his description of his mental state the next day suggests otherwise: 'I then slept, to awake the next morning with a clear head... A sensation of wellbeing and renewed life flowed through me. Breakfast tasted delicious and gave me extraordinary pleasure. When I later walked out into the garden, in which the sun shone now after a spring rain, everything glistened and sparkled in a fresh light. The world was as if newly created.'(Hofmann, 1980)

When LSD was first distributed by Sandoz pharmaceuticals in 1948, product guidelines stipulated two main applications: (1) analytical psychotherapy and (2) experimental studies on psychoses. The rationale for the former was that LSD could 'elicit [the] release of repressed material and provide mental relaxation for anxiety and obsessional neuroses', and, for the 
latter, that it could model aspects of psychosis and facilitate an understanding of its nature and pathogenesis (Hofmann, 1980). These two properties formed the basis of a large number of research projects with LSD in the 1950s and 1960s. However, the apparent paradox by which the same compound can be both a model of, and yet a treatment for, psychopathology has never been properly addressed.

In the early years of research with LSD, its remarkable potency (LSD is psychoactive in doses of $25 \mu \mathrm{g}$ or lower; Hintzen \& Passie, 2010) led psychiatrists to speculate about the existence of an endogenous LSD-like 'schizotoxin' in the brains of patients with schizophrenia (Osmond \& Smythies, 1952). In subsequent years, however, focus shifted more onto therapeutic applications, such as treating alcohol dependence, mood disorders and anxiety related to dying. Human research with LSD was brought to a halt in the late 1960s due to political pressure, motivated in part by reports of adverse psychological reactions among people using the drug improperly. Ironically, however, at the same time, reports of therapeutic success in the treatment of various psychiatric disorders were beginning to amount (Grinspoon \& Bakalar, 1979). In the last 18 months, five new reports on clinical research with LSD have appeared in the scientific press (Carhart-Harris et al. 2014a; Gasser et al. 2014; Schmid et al. 2014; Dolder et al. 2015; Kaelen et al. 2015), one of which focused on the drug's therapeutic effects (Gasser et al. 2014) and, another, its psychotomimetic effects (Schmid et al. 2014).

Clinical research with psychedelics is currently undergoing a major revival and modern studies are documenting the same paradoxical properties that were historically described with LSD. For example, in a controlled study in healthy volunteers, high-dose psilocybin produced strong or extreme fear in $30 \%$ of healthy volunteers and yet $80 \%$ reported improvements in wellbeing after the experience, with none reporting any decreases (Griffiths et al. 2006). Remarkably, in follow-up of the same sample, 65\% reported improved wellbeing 14 months after their (single) psilocybin experience (Griffiths et al. 2008) and significant increases in the personality trait openness were also evident (MacLean et al. 2011). These finding in healthy volunteers are supplemented by an increasing number of patient studies. Clinical improvements have been observed with psilocybin-assisted psychotherapy for the treatment of tobacco (Johnson et al. 2014) and alcohol addiction (Bogenschutz et al. 2015), obsessive-compulsive disorder (Moreno et al. 2006) and anxiety related to dying (Grob et al. 2011). Many of these reports mention some psychological discomfort during the acute experience; yet, the therapeutic benefits have been impressive and enduring.
Case reports of persistent psychological problems apparently precipitated by a psychedelic have considerable potential to excite alarm (Reich \& Hepps, 1972). However, such cases are rare and largely restricted to recreational use. Evidence does not support the view that psychedelics are harmful to mental health (Hendricks et al. 2015). Indeed, to the contrary, two recent population studies found decreased rates of suicidality and psychological distress among persons reporting previous use of psychedelics (Hendricks et al. 2015) and no evidence of any increased rates of mental health problems (Krebs \& Johansen, 2013). Similarly, large meta-analyses of controlled research have found that cases of mental health complications following exposure to a psychedelic are extremely rare (i.e. $<0.1 \%$ ), even in vulnerable populations (i.e. $<0.2 \%$ ), and are rarer still if volunteers are properly screened (Cohen \& Ditman, 1962; Studerus et al. 2011).

The main aim of the present study was to investigate the acute and 'mid-term' (i.e. 2 weeks after the acute experience) psychological effects of LSD in a placebocontrolled study in healthy volunteers. Validated measures of personality, optimism and psychotic symptoms were collected at baseline and 2 weeks post-LSD/placebo and measures of mood, cognition and psychotomimetic states were collected at the end of each dosing day. It was predicted that LSD would induce emotional lability and psychosis-like symptoms acutely but increase psychological wellbeing and openness in the longer term.

\section{Method}

\section{Experimental design}

This was a placebo-controlled, within-subjects/crossover study, with a balanced-order design. A total of 20 healthy volunteers were recruited to the study via word of mouth. The study received a favourable opinion from NRES Committee London-West London and was conducted in accordance with Good Clinical Practice guidelines, NHS Research Governance Framework and complied with the ethical standards of the declaration of Helsinki (1975, revised 2008). Imperial College London sponsored the research and a Home Office license was obtained for research with schedule one drugs. All volunteers were sent a study information sheet and asked to read it before their screening visit.

Volunteers made three study visits: screening, dosing session 1 and dosing session 2. Dosing sessions were separated by at least 2 weeks in every case and the order of receipt of LSD was balanced, i.e. half of the volunteers received LSD in dosing session 1 and 
half in dosing session 2. Volunteers were blind to the dosing order but the research team was not. Dosing order was determined sequentially so that all oddnumbered volunteers (i.e. S1 was the first volunteer recruited and S20 was the last) received LSD in dosing session 1, whereas all even-numbered volunteers received it in dosing session 2 . Subjective ratings were completed electronically and remotely soon after screening (baseline) and 2 weeks after a dosing session and sent to the researchers via email. Volunteers were instructed to complete the questionnaires in a quiet space without rushing. Two questionnaires pertaining to the acute drug experience were completed electronically within the research centre at the close of dosing days.

\section{Screening}

Prior to study enrolment, volunteers attended a screening visit at the Imperial Clinical Research Facility (ICRF) at the Hammersmith Hospital in West London. The study design, procedures and psychological effects of LSD were explained and signed informed consent taken. Key exclusion criteria were: $<21$ years of age, personal history of diagnosed psychiatric illness, immediate family history of a psychotic disorder, an absence of previous experience with a classic psychedelic drug (e.g. LSD, mescaline, psilocybin/magic mushrooms or dimethyltryptamine/ayahuasca), pregnancy, problematic alcohol use (assessed via psychiatric interview and reported weekly units), or a medically significant condition rendering the volunteer unsuitable for the study. The decision to recruit only individuals with prior experience with psychedelics was motivated by safety considerations, i.e. to minimize the risk of an adverse response to the drug. Screening involved routine blood tests, electrocardiogram, heart rate, blood pressure and a brief neurological examination. All enrolled participants were deemed physically and mentally healthy by the study psychiatrist, and none had histories of drug or alcohol dependence or diagnosed psychiatric disorder. Volunteers were asked to remain abstinent from alcohol the evening before a dosing day and to refrain from using other recreational drugs for the duration of the study.

\section{Study procedures}

Participants were asked to arrive at the study centre (Cardiff University's Brain Research Imaging Centre, CUBRIC) at a specific time at or before 09.00 hours. A urine test for drugs of abuse and pregnancy (where relevant) was carried out. Participants were re-briefed about the procedures for the day and any recent drug and alcohol use was documented. The study physician inserted a cannula into a vein in the antecubital fossa in preparation for intravenous (i.v.) dosing and the volunteer was encouraged to relax prior to drug/placebo administration. The dose of LSD was $75 \mu \mathrm{g}$ (by mouth; p.o.) in $10 \mathrm{ml}$ saline. Previous research has found this dose to produce robust psychological effects that are generally well tolerated (Carhart-Harris et al. 2014a). Placebo was $10 \mathrm{ml}$ saline (i.v.). Both solutions were infused over $2 \mathrm{~min}$.

After dosing, volunteers completed a functional neuroimaging protocol. This aspect of the study will be covered in detail in separate publications. In brief, subjects spent a period habituating to a scanner environment in a mock magnetic resonance imaging (MRI) scanner before entering a real MRI scanner $(1 \mathrm{~h}$ postdosing). The MRI scanning session lasted for $1 \mathrm{~h}$ after which a structured interview was performed and some ratings completed. Participants entered a magnetoencephalography (MEG) scanner approximately $3.5 \mathrm{~h}$ post-dosing. MEG scanning lasted for just over $1 \mathrm{~h}$. Participants were then interviewed and completed a battery of cognitive and behavioural tests (these will be detailed in a separate publication). Tasks were completed 6-7 h post-dosing.

The subjective effects of LSD were detected approximately $10 \mathrm{~min}$ post-infusion, peaked approximately $120 \mathrm{~min}$ post-infusion, and subsided to a negligible level approximately $7-8 \mathrm{~h}$ post-infusion. Participants were discharged by the study physician when they were considered to be functioning normally. Volunteers were either picked up by a friend or partner, ordered a taxi, or accompanied home by the research team as far as was feasible. Volunteers were asked to contact a researcher via telephone or text message once they had arrived home safely. A study psychiatrist was present for the duration of each dosing session and one researcher was allocated to each participant to assist them throughout the day. For each participant, the same researcher was present for both dosing days.

\section{Main outcomes and measures}

\section{Acute outcomes}

Participants completed two questionnaires at the end of each study day before being discharged by the study physician. These questionnaires enquired about different aspects of the subjective experience. The first was the Altered States of Consciousness questionnaire (ASC), a well validated and widely used tool for defining different altered states of consciousness that has been usefully revised in recent years (Studerus et al. 2010) and the second was the Psychotomimetic States Inventory (PSI), a tool developed to probe the psychotomimetic effects of different drugs (Mason 
et al. 2008). Participants were asked to complete the questionnaires with reference to the peak subjective effects of LSD (i.e. when the effects were most intense) or with reference to how they generally felt throughout the day - e.g. if they did not notice any effects.

\section{Mid-term outcomes}

Mid-term outcomes were completed 2 weeks after each dosing session (as well as at baseline) and these included: the Revised Life Orientation Test (LOT-R; Glaesmer et al. 2012), the Revised NEO Personality Inventory (NEO PI-R; Costa \& McCrae, 1995) and Peters' Delusions Inventory (PDI; Peters et al. 1999). The LOT-R was chosen as it is a well-validated measure of trait or dispositional optimism (Scheier et al. 1994), the NEO PI-R was chosen as it is well-validated and previous research has shown its sensitivity to the enduring effects of psychedelics (MacLean et al. 2011), and the PDI was chosen as it is a well-validated measure of delusional thinking that has shown to be sensitive to psychotic-like symptoms in the general population (Peters et al. 1999).

\section{Additional measures}

Additional questionnaires completed at baseline included the Beck Depression Inventory (BDI; Beck et al. 1961), the Quick Inventory of Depressive Symptomatology (QIDS; Rush et al. 2003), the StateTrait Anxiety Inventory (STAI; Hodgues \& Spielberger, 1969), the Ruminative Response Scale (RRS; Roelofs et al. 2006), the Dysfunctional Attitudes Scale (DAS; Floyd et al. 2004) and the modified version of the Tellegen Absorption Scale (MODTAS; Tellegen \& Atkinson, 1974).

\section{Data analysis}

Repeated-measures analyses of variance (ANOVAs) were used to test between-condition differences in the ASC, PSI and PDI, which have multiple factors. However, since a strong prior hypothesis was held that the personality trait 'openness' would be significantly increased post-LSD (MacLean et al. 2011), this was analysed using a paired $t$ test rather than an ANOVA. The remaining four personality dimensions in the NEO PI-R were analysed using paired $t$ tests with Bonferonni correction for multiple comparisons. A paired $t$ test was used to analyse changes in the LOT-R, as this has only one dimension. To test for order confounds in relation to primary outcomes, order was included as a variable in significant tests, and to further test for the influence of placebo/participation, baseline versus 2 weeks post-placebo differences in outcomes were tested for those who received placebo in their first dosing session (potential carryover effects of LSD precludes the inclusion of those who received placebo in their second dosing session). Effect sizes (Cohen's $d$ ) were calculated for primary outcomes. For correlational analyses, Pearson productmoment coefficients were calculated and two-tailed hypotheses tested. The problem of multiple comparisons was accounted for by Bonferonni correction.

\section{Results \\ Participants}

A total of 20 healthy volunteers participated in the study (four females, mean age $=30.9$, s.D. $=7.8$, range $=22-47$ years). All had at least one previous experience with a classic psychedelic drug (mean estimated LSD uses $=14$, S.D. $=17.8$, range $=0-70$ ) but not within 14 days of the first dosing session (mean last use of $\mathrm{LSD}=899.3, \quad$ S.D. $=1363, \quad$ range $=14-5400$ days). Self-estimates of other drug use were as follows: mean weekly alcohol units $=10.3$ (s.D. $=9$ ); mean number of daily cigarettes $=0.3$ (S.D. $=1.1$, range $=0-5$ ); mean number of cannabis uses $=705$ (s.D. $=639$, range =30-2000); mean number of 3,4-methylenedioxymethamphetamine $(\mathrm{MDMA})$ uses $=27$ (s.D. $=24$, range $=2-100)$; mean number of psilocybin/magic mushroom uses $=9.4$ (s.D. $=7.8$, range $=1-35$ ); mean number of ketamine uses $=3.6 \quad$ (S.D. $=5$, range $=0-20) ;$ mean number of cocaine uses $=9.6$ (S.D. $=9.4$, range $=0-30$ ) . Other mean baseline scores were as follows: $\mathrm{BDI}=0.6$ (S.D. $=0.9$, range $=0-3) ; \mathrm{QIDS}=4.2$ (S.D. $=3.1$, range $=0$ $10)$; $\mathrm{DAS}=105.5$ (S.D. $=23$, range $=55-146$ ); $\mathrm{RRS}=35.4$ (S.D. $=7.9$, range $=24-52$ ); $\mathrm{STAI}=29.2$ (S.D. $=4.6$, range $=20-38)$; MODTAS $=58.3$ (s.D. $=19.8$, range $=19-89)$.

\section{Acute subjective effects of LSD}

A repeated-measures ANOVA revealed a significant main effect of drug $\left(F_{1,19}=82.6, p<0.001\right)$ and a significant drug $\times$ ASC interaction $\left(F_{1,19}=10.3, p<0.001\right)$. Post-hoc $t$ tests revealed that all 11 dimensions or factors of the ASC were rated significantly higher after LSD than placebo $(p<0.01)$. Mean scores for each factor are displayed in the radar chart in Fig. 1. It is notable that although the LSD experience was dominated by changes in visual perception (i.e. elementary imagery, complex imagery and audio-visual synaesthesia), the factor 'blissful state' was markedly elevated under the drug $(+0.37$, s.D. $=0.28$, Cohen's $d$ $=1.65$ ). Although still significantly increased, the factor 'anxiety' was the least elevated under LSD (+0.15, S.D. $=0.2$, Cohen's $d=1.03$ ). These results indicate a marked increase in emotional arousal and lability under LSD but with a distinct bias towards positive affect. Reinforcing this, a $t$ test revealed that increases in 


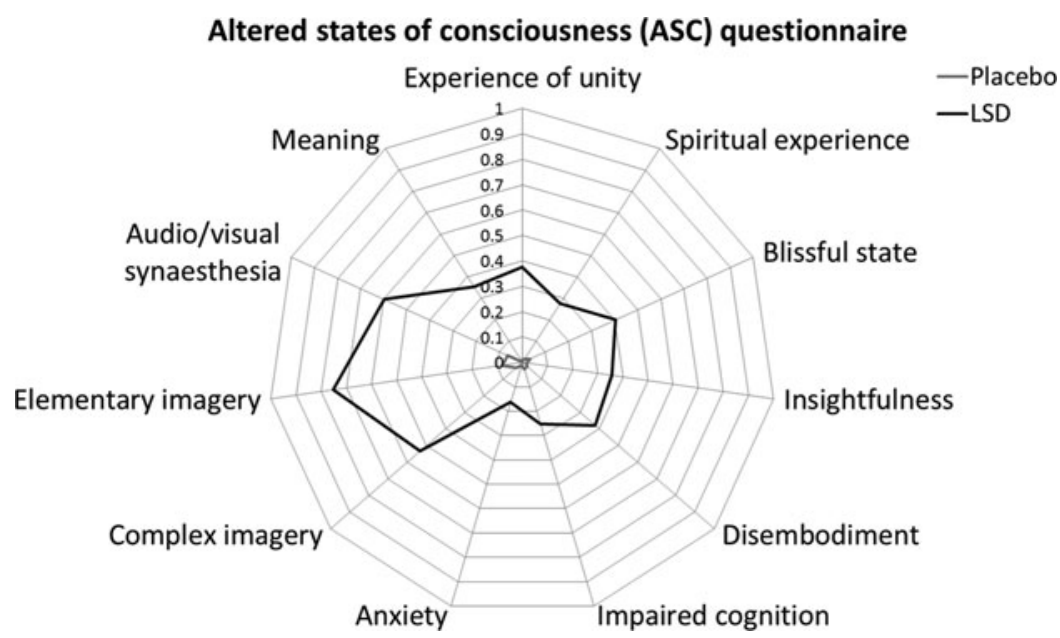

Fig. 1. Acute effects of lysergic acid diethylamide (LSD) measured via the Altered States of Consciousness questionnaire (ASC). Displayed are the mean scores on each of the 11 dimensions of the ASC for the LSD and placebo conditions.

'blissful state' under LSD were significantly greater than increases in 'anxiety' $[t=-3.7$, degrees of freedom $(\mathrm{df})=19, p<0.01$, Cohen's $d=0.91$ ].

A repeated-measures ANOVA revealed a significant main effect of condition on the PSI $\left(F_{1,19}=65.19, p<\right.$ $0.001)$ and a significant condition $\times$ PSI interaction $\left(F_{5,95}=35.2, p<0.001\right)$. Mean scores for each factor of the PSI are shown in the bar chart in Fig. 2. Post-hoc $t$ tests revealed that all factors, except 'anhedonia', were significantly increased under the drug $(p<0.01)$. The most marked effect was on 'cognitive disorganization' (Cohen's $d=2.37$ ) which is related to thought disorder in psychosis, but other highly characteristic aspects of psychosis such as 'delusional thinking' (Cohen's $d=1.63$ ) and 'paranoia' (Cohen's $d=0.83$ ) were also markedly increased under the drug.

\section{Mid-term subjective effects of LSD}

Optimism was significantly increased 2 weeks after LSD $(t=2.91, \mathrm{df}=18, p=0.005$, Cohen's $d=0.56)$, as was trait openness $(t=1.95, \mathrm{df}=19, p=0.03$, Cohen's $d=0.16$ ) (Fig. 3), and there were no such changes in optimism or personality post-placebo. In exploratory $t$ tests, there was a trend towards an increase in trait agreeableness post-LSD $(t=2.2, \quad \mathrm{df}=19, \quad p=0.038$, Cohen's $d=0.21$ ); however, this did not survive correction for multiple comparisons [corrected $p=$ 0.15].

Repeated-measures ANOVA found no change in delusional thinking (PDI scores) 2 weeks after LSD ( $p>$ 0.05). In fact, exploratory $t$ tests suggested a trend towards less distress $(t=1.92, \mathrm{df}=19, p=0.068)$ and preoccupation with 'delusional thoughts' $(t=1.92, \mathrm{df}=$ 19, $p=0.07$ ) but these trends were not significant, even before correction for multiple comparisons. There were no changes in PDI scores post-placebo.

\section{Predictors of the mid-term effects of LSD}

Regarding baseline predictors of the mid-term effects of LSD, focus was placed on personality (as measured by the NEO PI-R), depression (measured by the QIDS) and anxiety (measured by the STAI). A negative correlation was found between baseline agreeableness and increases in optimism post-LSD $\left(r=-0.56, r^{2}=0.31, p\right.$ $=0.014$ ) and positive correlations were found between baseline depression $\left(r=0.53, r^{2}=0.28, p=0.024\right)$ and anxiety $\left(r=0.49, r^{2}=0.24, p=0.04\right)$ and the post-LSD increases in openness. However, none of these survived correction for multiple comparisons (revised $p$ $=0.05 / 7=0.007)$.

Regarding acute predictors of the mid-term effects of LSD, there was a negative correlation between acute anxiety (ASC) and post-LSD increases in optimism $(r$ $\left.=-0.47, r^{2}=0.22, n=19, p=0.04\right)$ and positive correlations between impaired/disorganized cognition scores on the ASC and PSI and post-LSD increases in openness (ASC: $r=0.44, r^{2}=0.2, n=20, p=0.049$; PSI: $r=$ $\left.0.52, r^{2}=0.26, n=20, p=0.019\right)$ but these correlations also failed to survive correction for multiple comparisons (revised $p=0.5 / 17=0.003$ ).

\section{Discussion}

The primary aim of this study was to investigate the acute and mid-term subjective effects of LSD in a controlled study in order to advance our understanding of its psychological effects. It was hypothesized that LSD would increase emotional lability and psychosis-like symptoms acutely, and increase optimism and 


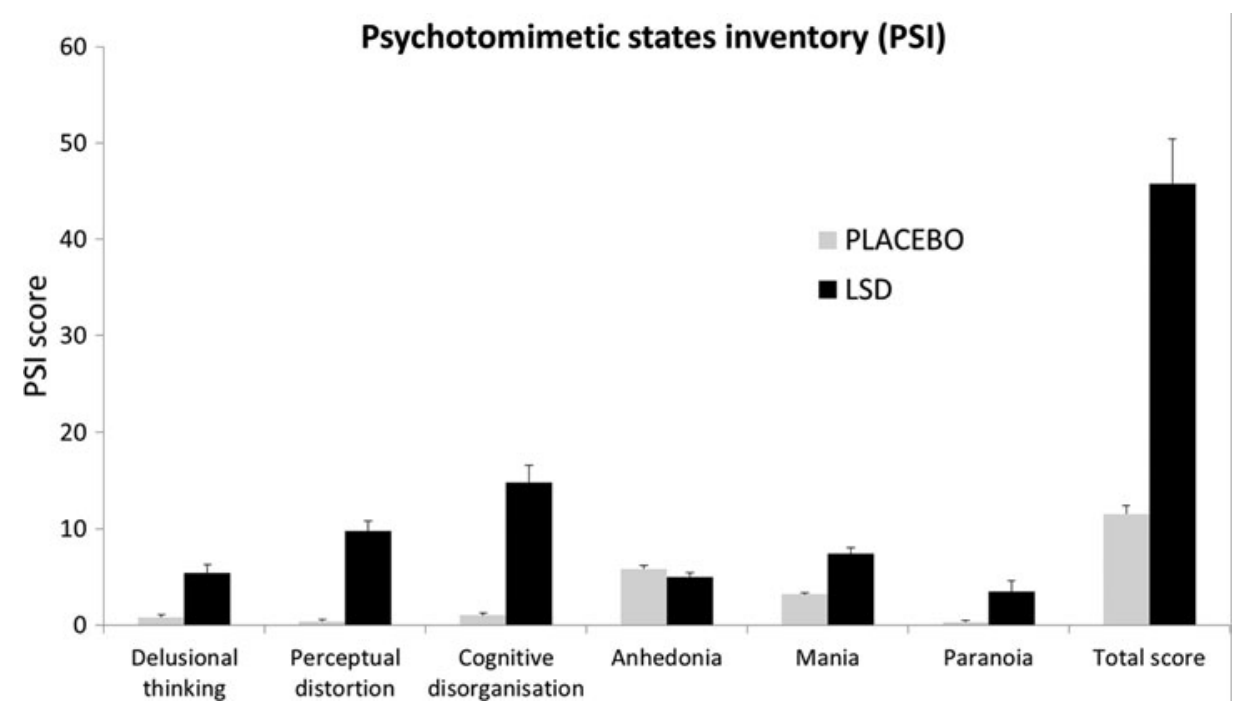

Fig. 2. Acute effects measured of lysergic acid diethylamide (LSD) measured via the Psychotomimetic States Inventory (PSI). Values are the mean scores plus the positive standard errors of the mean (S.E.M.) for each of the six factors of the PSI, plus the total score (which is a sum of the scores of the six factors). All factors, except for anhedonia, were scored significantly higher under LSD than placebo.

openness 2 weeks later, and these hypotheses were supported by the data.

Focusing first on LSD's acute effects, scores on the PSI reinforce the view that LSD is a potent psychotomimetic. Previous studies have examined PSI scores after sleep deprivation (Petrovsky et al. 2014), dreaming (Mason \& Wakerley, 2012), cannabis (Mason et al. 2008), tetrahydrocannabinol (THC) (Stokes et al. 2009) and ketamine intoxication (Mason et al. 2008). Although both dreaming and sleep deprivation elevated subscales of the PSI, only the aforementioned drugs produced appreciable psychosis-like symptoms - and still not to the same extent as LSD in the present study. For example, mean total scores on the PSI were 24 (S.D. $=10.9)$ post-ketamine infusion $(150$ $\mathrm{mg} / \mathrm{ml}$ plasma), 15.9 (s.D. = 11) post-THC (10 mg, p.o.) and 33.3 (S.D. = 19.5) post-cannabis use (smoked, quantity unknown), whereas the mean total PSI score in the present study was 45.8 (S.D. $=21$ ). To our knowledge, only cannabis in highly schizotypal individuals (Mason et al. 2009) has produced PSI scores of an equivalent magnitude to those seen here with LSD.

More generally, relatively strong subjective effects were produced by the present dose of LSD (i.e. 75 $\mu \mathrm{g}$, i.v.) as indexed by the ASC. In previous studies, psilocybin (115-350 $\mu \mathrm{g} / \mathrm{kg}$, p.o.), MDMA (1.5-1.7 $\mathrm{mg} / \mathrm{kg}$, p.o.) and ketamine (6-12 $\mu \mathrm{g} / \mathrm{kg}$ per min, i.v.) produced effects of a lower magnitude than those seen here (Studerus et al. 2010) but in a recent study with $200 \mu \mathrm{g}$ LSD (p.o.), ASC scores were of a similar magnitude to those observed here (Schmid et al. 2014).

With the PSI results in mind, it is worth briefly discussing the relative merits of different drug models of psychosis. Ketamine is often described as an especially meritorious model of psychosis because it can induce both positive and negative symptoms (Krystal et al. 1994). However, the premise that negative symptoms can be modelled by an acute drug state is questionable (Carhart-Harris et al. 2013). For example, it has been argued that negative symptoms are non-specific for psychosis (i.e. they are also prevalent in depression; Kaiser et al. 2011; Carhart-Harris et al. 2013). Positive symptoms are specific for psychosis, but comparison studies have suggested that these are better modelled by classic psychedelics than ketamine (Gouzoulis-Mayfrank et al. 2005; Carhart-Harris et al. 2013). Others have shown that THC is a particularly potent inducer of positive psychotic symptoms (Morrison et al. 2009). Thus, future studies might compare the psychotomimetic properties of THC, ketamine and a classic psychedelic in a controlled, cross-over design to systematically assess the relative value of these different models.

Based on the PSI results, one might infer that participants' acute LSD experiences were dominated by unpleasant psychosis-like phenomena; however, this was not the case. Some volunteers did show frank psychotic phenomena during their LSD experiences (e.g. paranoid and delusional thinking) but at the group level, positive mood was more common. For example, scores on the (positively valenced) 'blissful experience' dimension of the ASC were significantly higher than scores on the (negatively valenced) 'anxiety' dimension. Consistent with the view that LSD is more likely to produce positive than negative mood, a separate study with LSD (200 $\mu$ g, p.o.) reported marked 
(a)

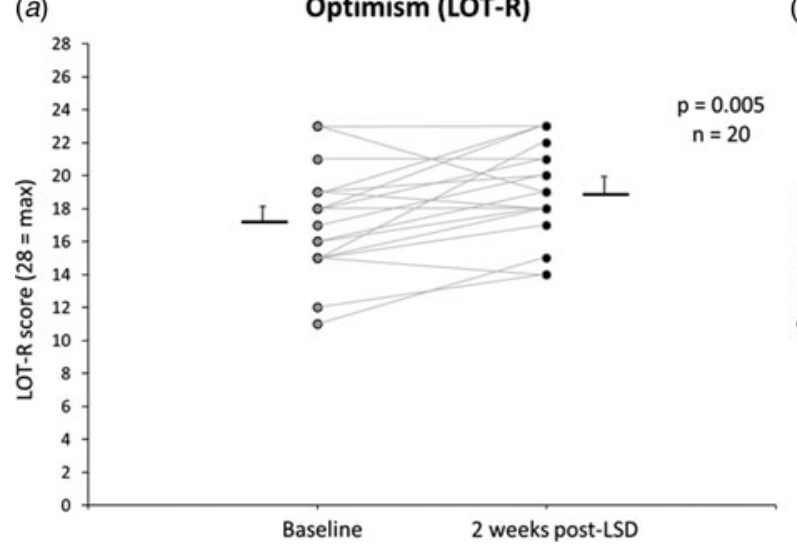

(b)

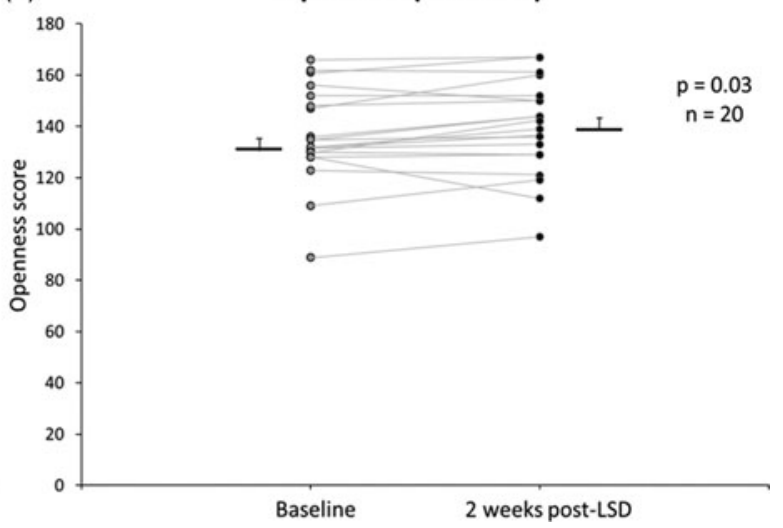

Fig. 3. Mid-term effects of lysergic acid diethylamide (LSD). These charts display paired data points for optimism (a) and openness $(b)$ scores at baseline and 2 weeks after LSD for each participant. Also displayed on each chart are the mean scores (horizontal bars) and the positive standard errors of the mean (S.E.M.). Both optimism and openness were significantly increased after LSD. There was no effect of order of receipt of LSD nor were there any changes in optimism or personality 2 weeks after receipt of placebo. LOT-R, Revised Life Orientation Test; NEO PI-R, Revised NEO Personality Inventory.

positive mood effects, described as 'MDMA-like' (Schmid et al. 2014); an important caveat, however, is that both the Schmid et al. study and the present one recruited volunteers with previous experience with psychedelics. Thus, positive prior experiences and positive regard towards LSD may have biased outcomes.

The findings that optimism and openness are increased 2 weeks after LSD are consistent with previous findings (Griffiths et al. 2006, 2008; MacLean et al. 2011), suggesting that improved psychological wellbeing and increased openness are relatively reliable mid- to long-term effects of psychedelics. That there were no increases in psychotic symptomatology at the 2 week end point is also consistent with reports of preserved or even improved mental health among populations of people that have used psychedelic drugs (Bouso et al. 2012; Krebs \& Johansen, 2013; Hendricks et al. 2015). These results are also consistent with previous findings that psychedelics can be useful in treating certain psychiatric disorders (Moreno et al. 2006; Grob et al. 2011; Gasser et al. 2014; Johnson et al. 2014; Bogenschutz et al. 2015) as well as the notion that they may have therapeutic potential in the treatment of mood disorders such as depression (Carhart-Harris et al. 2014b). High dispositional optimism is associated with a range of positive health and socio-economic outcomes (Carver \& Scheier, 2014); thus, the increases in optimism observed here may be treated as further evidence of the therapeutic potential of psychedelic drugs.

A limitation of the present study was the relatively short duration of the follow-up period (i.e. 2 weeks); however, longer-term follow-up is planned and 2 weeks is still relevant when considering potential therapeutic applications (Zarate et al. 2006). Another limitation is the single-blind design; however, the classic double-blind model can feel contrived in the context of controlled studies with psychoactive compounds such as LSD, since the blind is almost universally ineffective. A single-blind design allowed us to introduce some uncertainty, however, and so was considered better than an entirely open-label design. The inclusion of an 'active placebo' condition might improve the ineffectiveness of the blind in studies with psychedelics; however, an inert placebo was required in the present study in order to provide a valid baseline for the neuroimaging contrasts. Related to this, a final limitation is that the LSD and placebo sessions involved MRI and MEG scans that each lasted for over $60 \mathrm{~min}$. Brain imaging environments can be demanding for some individuals, particularly under the influence of psychedelics (Studerus et al. 2011). Individuals are known to be especially sensitive to the environment in which they experience the effects of a psychedelic (Johnson et al. 2008), and so the drug plus scanner combination may have contributed to the especially high PSI scores observed here with LSD.

With these caveats entered, it is important to attempt an explanation of how LSD can be both acutely psychotomimetic and yet psychologically beneficial in the mid to long term, and insights from neurobiology may be helpful in this regard. There is a consensus that serotonin $2 \mathrm{~A}$ receptor $\left(5-\mathrm{HT}_{2 \mathrm{~A}} \mathrm{R}\right)$ agonism is central to the psychopharmacology of psychedelics, e.g. affinity for the $5-\mathrm{HT}_{2 \mathrm{~A}} \mathrm{R}$ correlates strongly with their potencies (Glennon et al. 1984), and pre-treatment with a $5-\mathrm{HT}_{2 \mathrm{~A}} \mathrm{R}$ antagonist effectively abolishes the classic 'psychedelic' effects of psilocybin 


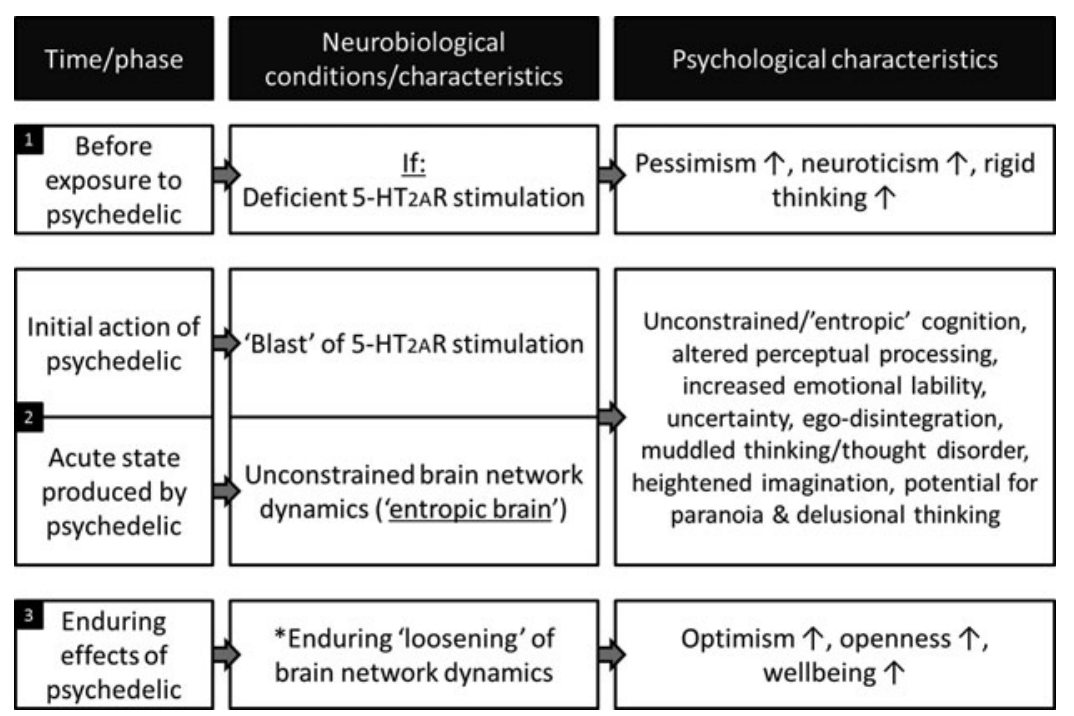

Fig. 4. Action of psychedelics on the mind and brain: This empirically informed model illustrates the hypothesized relationship between three different neurobiological or physiological states and their psychological counterparts. Specifically, it is predicted that deficient serotonin $2 \mathrm{~A}$ receptor $\left(5-\mathrm{HT}_{2 \mathrm{~A}} \mathrm{R}\right)$ stimulation has a stultifying influence on cognition, promoting pessimism, neuroticism and rigid thinking (phase 1). Informed by neuroimaging studies with psychedelics (Carhart-Harris et al. 2014b), 5- $\mathrm{HT}_{2 \mathrm{~A}} \mathrm{R}$ stimulation is associated with unconstrained brain network dynamics and the characteristic 'entropic' quality of cognition in the psychedelic state (phase 2). Finally, it is hypothesized that an acute 'onslaught' or 'blast' of $5-\mathrm{HT}_{2 \mathrm{~A}} \mathrm{R}$ stimulation, via the action of a psychedelic, has a residual influence on brain network dynamics and associated cognition (phase 3). 5- $\mathrm{HT}_{2 \mathrm{~A}} \mathrm{R}$ stimulation is described as having a 'loosening' or 'lubricating' influence on cognition and this is hypothesized to be conducive to improved psychological wellbeing. ${ }^{*}$ The long-term effects of psychedelics on brain network dynamics have yet to be formally investigated.

(Vollenweider et al. 1998). The principal psychological purpose or function of the $5-\mathrm{HT}_{2 \mathrm{~A}} \mathrm{R}$ is poorly understood; however, it is known that $5-\mathrm{HT}_{2 \mathrm{~A}} \mathrm{R}$ stimulation promotes certain aspects of learning (Harvey, 2003; Harvey et al. 2004; Romano et al. 2010) and cognition (King et al. 1972; Williams et al. 2002). Specifically, $5-\mathrm{HT}_{2 \mathrm{~A}} \mathrm{R}$ stimulation enhances the flexibility of cognition (Boulougouris et al. 2008), which may be related to reports of enhanced imagination (Carhart-Harris et al. 2014a) and creative thinking (Frecska et al. 2012) with psychedelics. Interestingly, an association has been found between positive mood and flexible, creative thinking (Hirt et al. 2008; Lin et al. 2014) and this may explain why both are associated with psychedelics. Indeed, the positive mood effects of psilocybin (a direct $5-\mathrm{HT}_{2 \mathrm{~A}} \mathrm{R}$ agonist) and MDMA (a potent serotonin 'releaser') are significantly attenuated by pretreatment with the 5- $\mathrm{HT}_{2 \mathrm{~A}} \mathrm{R}$ antagonist ketanserin (Kometer et al. 2012; Van Wel et al. 2012).

Psychedelics also transiently impair certain aspects of cognition, however, such as the ability to focus and concentrate (Umbricht et al. 2003; Vollenweider et al. 2007), which is consistent with the high ratings of impaired cognition in the present study (Figs. 1 and 2). It is also important to acknowledge that while $5-\mathrm{HT}_{2 \mathrm{~A}} \mathrm{R}$ antagonism attenuates the positive mood effects of psilocybin (and MDMA), it also attenuates the positive psychotic symptoms that can be produced by the drug (Carter et al. 2007) and $5-\mathrm{HT}_{2 \mathrm{~A}} \mathrm{R}$ agonism has been linked with anxiety-related behaviours in rodents (Weisstaub et al. 2006).

Thus, $5-\mathrm{HT}_{2 \mathrm{~A}} \mathrm{R}$ stimulation has been associated with both positive and negative facets of the acute psychedelic state (i.e. positive mood but also anxiety and psychotic symptoms), so how can we reconcile these things with each other? Is there a more fundamental action of psychedelics that can explain both effects? As reported above, $5-\mathrm{HT}_{2 \mathrm{~A}} \mathrm{R}$ stimulation has been associated with enhanced cognitive flexibility, and inspired by recent neuroimaging findings (CarhartHarris et al. 2012; Muthukumaraswamy et al. 2013; Petri et al. 2014; Roseman et al. 2014; Tagliazucchi et al. 2014), the psychedelic state has been characterized as an 'entropic' state in which the mind/brain operates outside of its normal, optimal level of order, in a realm of relative disorder (Carhart-Harris et al. 2014b). It may be that what underlies both facets of the psychedelic state and can resolve the 'valence paradox' therefore, is this principle of increased cognitive entropy (see Fig. 4). Accordingly, we predict that disordered or entropic cognition is a more fundamental characteristic of the psychedelic state than either positive or negative mood. This hypothesis could be tested by carrying out a principal components analysis of the ASC data; 
we would predict that valence non-specific items and particularly those related to 'entropic cognition' (such as loss of self/ego, loss of ego-boundaries, altered meaning and muddled thinking) would load more heavily onto the first principal component than valence-specific items (such as feeling euphoric or sad) - e.g. see Lebedev et al. (2015). Acute entropic processes may also be useful predictors of the $\mathrm{mid} /$ longterms effects of psychedelics, and the (trend-level) relationship between impaired/disordered cognition and subsequent increases in trait openness might be suggestive of such an association.

Before concluding, it is worth considering one final important matter. The discussion so far has focused mainly on the paradoxical acute psychological effects of psychedelics. However, as the present results have demonstrated, the acute effects of psychedelics can be quite different to their longer-term effects, and it is arguably the latter that are more clinically relevant. Previous studies have shown that trait characteristics, such as personality and outlook, can be significantly altered by psychedelics (Griffiths et al. 2008; MacLean et al. 2011). Moreover, associations have been found between certain psychological traits and the $5-\mathrm{HT}_{2 \mathrm{~A}} \mathrm{R}$ (Turecki et al. 1999; Meyer et al. 2003; Ott et al. 2005; Bhagwagar et al. 2006; Frokjaer et al. 2008). Specifically, deficient $5-\mathrm{HT}_{2 \mathrm{~A}} \mathrm{R}$ stimulation has been linked with depression-related behaviours such as suicide (Turecki et al. 1999), dysfunctional or excessively pessimistic attitudes (Meyer et al. 2003; Bhagwagar et al. 2006) and neuroticism (Frokjaer et al. 2008). In this context, increased psychological wellbeing (Griffiths et al. 2008), openness (MacLean et al. 2011), decreased suicidality (Hendricks et al. 2015) and now increased optimism after a 'blast' of $5-\mathrm{HT}_{2 \mathrm{~A}} \mathrm{R}$ stimulation may begin to make functional sense. We predict that deficient $5-\mathrm{HT}_{2 \mathrm{~A}} \mathrm{R}$ stimulation causes cognition to 'stultify', whereas 5- $\mathrm{HT}_{2 \mathrm{~A}} \mathrm{R}$ stimulation loosens cognition and associated brain dynamics, serving as a metaphorical 'lubricant' for the mind and brain. We predict that this loosening effect persists beyond the acute intoxication phase and can potentially explain the mid- to long-term psychological effects of psychedelics. Recent reports of enduring brain changes with $5-\mathrm{HT}_{2 \mathrm{~A}} \mathrm{R}$ stimulation and psychedelic drug-use (Bouso et al. 2015), as well as speculations on the function of serotonin in the brain (Branchi, 2011), may herald the beginnings of an understanding of this important matter. We intend to detail the acute brain effects of LSD in forthcoming neuroimaging papers and to investigate the long-term psychological and brain effects of psychedelics in future studies.

In conclusion, this study sought to investigate the paradoxical psychological effects of LSD in a controlled study in healthy volunteers. LSD produced robust acute psychological effects that were characterized by psychosis-like symptoms but also positive mood. Mid-term effects included significant increases in optimism and the personality trait openness and no increases in delusional thinking. A mechanistic explanation for these findings was proposed based on the 'entropic brain' hypothesis (Carhart-Harris et al. 2014b).

\section{Acknowledgements}

This research received financial and intellectual support from the Beckley Foundation and was conducted as part of a wider Beckley-Imperial research programme. The researchers would also like to thank supporters of the Walacea.com crowd-funding campaign who played a crucial role in securing the completion of this study. The report presents independent research carried out at the National Institute of Health Research (NIHR)/Wellcome Trust Imperial Clinical Research Facility.

\section{Declaration of Interest}

None.

\section{References}

Beck AT, Ward CH, Mendelson M, Mock J, Erbaugh J (1961). An inventory for measuring depression. Archives of General Psychiatry 4, 561-571.

Bhagwagar Z, Hinz R, Taylor M, Fancy S, Cowen P, Grasby $\mathbf{P}$ (2006). Increased 5- $\mathrm{HT}_{2 \mathrm{~A}}$ receptor binding in euthymic, medication-free patients recovered from depression: a positron emission study with $\left[{ }^{11} \mathrm{C}\right] \mathrm{MDL} 100,907$. American Journal of Psychiatry 163, 1580-1587.

Bogenschutz MP, Forcehimes AA, Pommy JA, Wilcox CE, Barbosa P, Strassman RJ (2015). Psilocybin-assisted treatment for alcohol dependence: a proof-of-concept study. Journal of Psychopharmacology 29, 289-299.

\section{Boulougouris V, Glennon JC, Robbins TW (2008).} Dissociable effects of selective $5-\mathrm{HT}_{2 \mathrm{~A}}$ and $5-\mathrm{HT}_{2 \mathrm{C}}$ receptor antagonists on serial spatial reversal learning in rats. Neuropsychopharmacology 33, 2007-2019.

Bouso JC, González D, Fondevila S, Cutchet M, Fernández X, Ribeiro Barbosa PC, Alcázar-Córcoles MÁ, Araújo WS, Barbanoj MJ, Fábregas JM, Riba J (2012). Personality, psychopathology, life attitudes and neuropsychological performance among ritual users of Ayahuasca: a longitudinal study. PLOS ONE 7, e42421.

Bouso JC, Palhano-Fontes F, Rodríguez-Fornells A, Ribeiro S, Sanches R, Crippa JA, Hallak JE, De Araujo DB, Riba J (2015). Long-term use of psychedelic drugs is associated with differences in brain structure and personality in humans. European Neuropsychopharmacology 25, 483-492.

Branchi I (2011). The double edged sword of neural plasticity: increasing serotonin levels leads to both greater 
vulnerability to depression and improved capacity to recover. Psychoneuroendocrinology 36, 339-351.

Carhart-Harris R, Brugger S, Nutt D, Stone J (2013). Psychiatry's next top model: cause for a re-think on drug models of psychosis and other psychiatric disorders. Journal of Psychopharmacology 27, 771-778.

Carhart-Harris R, Kaelen M, Whalley M, Bolstridge M, Feilding A, Nutt D (2014a). LSD enhances suggestibility in healthy volunteers. Psychopharmacology (Berlin) 232, 785-794.

Carhart-Harris RL, Erritzoe D, Williams T, Stone JM, Reed LJ, Colasanti A, Tyacke RJ, Leech R, Malizia AL, Murphy K, Hobden P, Evans J, Feilding A, Wise RG, Nutt DJ (2012). Neural correlates of the psychedelic state as determined by fMRI studies with psilocybin. Proceedings of the National Academy of Sciences USA 109, 2138-2143.

Carhart-Harris RL, Leech R, Hellyer PJ, Shanahan M, Feilding A, Tagliazucchi E, Chialvo DR, Nutt D (2014b). The entropic brain: a theory of conscious states informed by neuroimaging research with psychedelic drugs. Frontiers in Human Neuroscience 8, 20.

Carter OL, Hasler F, Pettigrew JD, Wallis GM, Liu GB, Vollenweider FX (2007). Psilocybin links binocular rivalry switch rate to attention and subjective arousal levels in humans. Psychopharmacology (Berlin) 195, 415-424.

Carver CS, Scheier MF (2014). Dispositional optimism. Trends in Cognitive Science 18, 293-299.

Cohen S, Ditman KS (1962). Complications associated with lysergic acid diethylamide (LSD-25). JAMA 181, 161-162.

Costa PT Jr., McCrae RR (1995). Domains and facets: hierarchical personality assessment using the Revised NEO Personality Inventory. Journal of Personality Assessment 64, 21-50.

Dolder PC, Schmid Y, Haschke M, Rentsch KM, Liechti ME (2015). Pharmacokinetics and concentration-effect relationship of oral LSD in humans. International Journal of Neuropsychopharmacology. Published online 24 June 2015. doi:10.1093/ijnp/pyv072.

Floyd M, Scogin F, Chaplin WF (2004). The Dysfunctional Attitudes Scale: factor structure, reliability, and validity with older adults. Aging and Mental Health 8, 153-160.

Frecska E, More CE, Vargha A, Luna LE (2012). Enhancement of creative expression and entoptic phenomena as aftereffects of repeated ayahuasca ceremonies. Journal of Psychoactive Drugs 44, 191-199.

Frokjaer VG, Mortensen EL, Nielsen FA, Haugbol S, Pinborg LH, Adams KH, Svarer C, Hasselbalch SG, Holm S, Paulson OB, Knudsen GM (2008). Frontolimbic serotonin $2 \mathrm{~A}$ receptor binding in healthy subjects is associated with personality risk factors for affective disorder. Biological Psychiatry 63, 569-576.

Gasser P, Holstein D, Michel Y, Doblin R, Yazar-Klosinski B, Passie T, Brenneisen R (2014). Safety and efficacy of lysergic acid diethylamide-assisted psychotherapy for anxiety associated with life-threatening diseases. Journal of Nervous and Mental Diseases 202, 513-520.

Glaesmer H, Rief W, Martin A, Mewes R, Brahler E, Zenger M, Hinz A (2012). Psychometric properties and population- based norms of the Life Orientation Test Revised (LOT-R). British Journal of Health Psychology 17, 432-445.

Glennon RA, Titeler M, Mckenney JD (1984). Evidence for $5-\mathrm{HT}_{2}$ involvement in the mechanism of action of hallucinogenic agents. Life Sciences 35, 2505-2511.

Gouzoulis-Mayfrank E, Heekeren K, Neukirch A, Stoll M, Stock C, Obradovic M, Kovar KA (2005). Psychological effects of (S)-ketamine and $N, N$-dimethyltryptamine (DMT): a double-blind, cross-over study in healthy volunteers. Pharmacopsychiatry 38, 301-311.

Griffiths R, Richards W, Johnson M, McCann U, Jesse R (2008). Mystical-type experiences occasioned by psilocybin mediate the attribution of personal meaning and spiritual significance 14 months later. Journal of Psychopharmacology 22, 621-632.

Griffiths RR, Richards WA, McCann U, Jesse R (2006). Psilocybin can occasion mystical-type experiences having substantial and sustained personal meaning and spiritual significance. Psychopharmacology (Berlin) 187, 268-283, discussion 284-292.

Grinspoon L, Bakalar JB (1979). Psychedelic Drugs Reconsidered. Basic Books: New York.

Grob CS, Danforth AL, Chopra GS, Hagerty M, McKay CR, Halberstadt AL, Greer GR (2011). Pilot study of psilocybin treatment for anxiety in patients with advanced-stage cancer. Archives of General Psychiatry 68, 71-78.

Harvey JA (2003). Role of the serotonin $5-\mathrm{HT}_{2 \mathrm{~A}}$ receptor in learning. Learning and Memory 10, 355-362.

Harvey JA, Quinn JL, Liu R, Aloyo VJ, Romano AG (2004). Selective remodeling of rabbit frontal cortex: relationship between $5-\mathrm{HT}_{2 \mathrm{~A}}$ receptor density and associative learning. Psychopharmacology (Berlin) 172, 435-442.

Hendricks PS, Thorne CB, Clark CB, Coombs DW, Johnson MW (2015). Classic psychedelic use is associated with reduced psychological distress and suicidality in the United States adult population. Journal of Psychopharmacology 29, 280-288.

Hintzen A, Passie T (2010). The Pharmacology of LSD: A Critical Review. Oxford University Press: Oxford.

Hirt ER, Devers EE, Mccrea SM (2008). I want to be creative: exploring the role of hedonic contingency theory in the positive mood-cognitive flexibility link. Journal of Personality and Social Psychology 94, 214-230.

Hodgues WF, Spielberger CD (1969). An indicant of trait or state anxiety? Journal of Consultancy and Clinical Psychology 33, 430-434.

Hofmann A (1980). LSD: My Problem Child. McGraw-Hill: New York.

Johnson M, Richards W, Griffiths R (2008). Human hallucinogen research: guidelines for safety. Journal of Psychopharmacology 22, 603-620.

Johnson MW, Garcia-Romeu A, Cosimano MP, Griffiths RR (2014). Pilot study of the $5-\mathrm{HT}_{2 \mathrm{~A}} \mathrm{R}$ agonist psilocybin in the treatment of tobacco addiction. Journal of

Psychopharmacology 28, 983-992.

Kaelen M, Barrett FS, Roseman L, Lorenz R, Family N, Bolstridge M, Curran HV, Feilding A, Nutt DJ, Carhart-Harris RL (2015). LSD enhances the emotional 
response to music. Psychopharmacology (Berlin) 232, 36073614.

Kaiser S, Heekeren K, Simon JJ (2011). The negative symptoms of schizophrenia: category or continuum? Psychopathology 44, 345-353.

King AR, Martin IL, Seymour KA (1972). Reversal learning facilitated by a single injection of lysergic acid diethylamide (LSD 25) in the rat. British Journal of Pharmacology 45, 161P$162 \mathrm{P}$.

Kometer M, Schmidt A, Bachmann R, Studerus E, Seifritz E, Vollenweider FX (2012). Psilocybin biases facial recognition, goal-directed behavior, and mood state toward positive relative to negative emotions through different serotonergic subreceptors. Biological Psychiatry 72, 898-906.

Krebs TS, Johansen PO (2013). Psychedelics and mental health: a population study. PLOS ONE 8, e63972.

Krystal JH, Karper LP, Seibyl JP, Freeman GK, Delaney R, Bremner JD, Heninger GR, Bowers MB Jr., Charney DS (1994). Subanesthetic effects of the noncompetitive NMDA antagonist, ketamine, in humans. Psychotomimetic, perceptual, cognitive, and neuroendocrine responses. Archives of General Psychiatry 51, 199-214.

Lin WL, Tsai PH, Lin HY, Chen HC (2014). How does emotion influence different creative performances? The mediating role of cognitive flexibility. Cognition and Emotion 28, 834-844.

Lebedev AV, Lovden M, Rosenthal G, Feilding A, Nutt DJ, Carhart-Harris RL (2015). Finding the self by losing the self: neural correlates of ego-dissolution under psilocybin. Human Brain Mapping 36, 3137-3153.

Maclean KA, Johnson MW, Griffiths RR (2011). Mystical experiences occasioned by the hallucinogen psilocybin lead to increases in the personality domain of openness. Journal of Psychopharmacology 25, 1453-1461.

Mason O, Morgan CJ, Dhiman SK, Patel A, Parti N, Curran HV (2009). Acute cannabis use causes increased psychotomimetic experiences in individuals prone to psychosis. Psychological Medicine 39, 951-956.

Mason O, Wakerley D (2012). The psychotomimetic nature of dreams: an experimental study. Schizophrenia Research Treatment 2012, 872307.

Mason OJ, Morgan CJ, Stefanovic A, Curran HV (2008). The Psychotomimetic States Inventory (PSI): measuring psychotic-type experiences from ketamine and cannabis. Schizophrenia Research 103, 138-142.

Meyer JH, McMain S, Kennedy SH, Korman L, Brown GM, Dasilva JN, Wilson AA, Blak T, Eynan-Harvey R, Goulding VS, Houle S, Links P (2003). Dysfunctional attitudes and $5-\mathrm{HT}_{2}$ receptors during depression and selfharm. American Journal of Psychiatry 160, 90-99.

Moreno FA, Wiegand CB, Taitano EK, Delgado PL (2006). Safety, tolerability, and efficacy of psilocybin in 9 patients with obsessive-compulsive disorder. Journal of Clinical Psychiatry 67, 1735-1740.

Morrison PD, Zois V, Mckeown DA, Lee TD, Holt DW, Powell JF, Kapur S, Murray RM (2009). The acute effects of synthetic intravenous $\Delta^{9}$-tetrahydrocannabinol on psychosis, mood and cognitive functioning. Psychological Medicine 39, 1607-1616.
Muthukumaraswamy SD, Carhart-Harris RL, Moran RJ, Brookes MJ, Williams TM, Errtizoe D, Sessa B, Papadopoulos A, Bolstridge M, Singh KD, Feilding A, Friston KJ, Nutt DJ (2013). Broadband cortical desynchronization underlies the human psychedelic state. Journal of Neuroscience 33, 15171-15183.

Osmond H, Smythies J (1952). Schizophrenia: a new approach. Journal of Mental Science 98, 309-315.

Ott U, Reuter M, Hennig J, Vaitl D (2005). Evidence for a common biological basis of the absorption trait, hallucinogen effects, and positive symptoms: epistasis between $5-\mathrm{HT}_{2 \mathrm{a}}$ and COMT polymorphisms. American Journal of Medical Genetics. Part B, Biological Neuropsychiatric Genetics 137B, 29-32.

Peters ER, Joseph SA, Garety PA (1999). Measurement of delusional ideation in the normal population: introducing the PDI (Peters et al. Delusions Inventory). Schizophrenia Bulletin 25, 553-576.

Petri G, Expert P, Turkheimer F, Carhart-Harris R, Nutt D, Hellyer PJ, Vaccarino F (2014). Homological scaffolds of brain functional networks. Journal of the Royal Society Interface 11, 20140873.

Petrovsky N, Ettinger U, Hill A, Frenzel L, Meyhofer I, Wagner M, Backhaus J, Kumari V (2014). Sleep deprivation disrupts prepulse inhibition and induces psychosis-like symptoms in healthy humans. Journal of Neuroscience 34, 9134-9140.

Reich P, Hepps RB (1972). Homicide during a psychosis induced by LSD. JAMA 219, 869-871.

Roelofs J, Muris P, Huibers M, Peeters F, Arntz A (2006). On the measurement of rumination: a psychometric evaluation of the ruminative response scale and the rumination on sadness scale in undergraduates. Journal of Behavior Therapy and Experimental Psychiatry 37, 299-313.

Romano AG, Quinn JL, Li L, Dave KD, Schindler EA, Aloyo VJ, Harvey JA (2010). Intrahippocampal LSD accelerates learning and desensitizes the $5-\mathrm{HT}_{2 \mathrm{~A}}$ receptor in the rabbit, Romano et al. Psychopharmacology (Berlin) 212, 441-448.

Roseman L, Leech R, Nutt DJ, Feilding A, Carhart-Harris RL (2014). The effects of psilocybin and MDMA on betweennetwork resting state functional connectivity in healthy volunteers. Frontiers in Human Neuroscience 8, 204.

Rush AJ, Trivedi MH, Ibrahim HM, Carmody TJ, Arnow B, Klein DN, Markowitz JC, Ninan PT, Kornstein S, Manber R, Thase ME, Kocsis JH, Keller MB (2003). The 16-item Quick Inventory of Depressive Symptomatology (QIDS), clinician rating (QIDS-C), and self-report (QIDS-SR): a psychometric evaluation in patients with chronic major depression. Biological Psychiatry 54, 573-583.

Scheier MF, Carver CS, Bridges MW (1994). Distinguishing optimism from neuroticism (and trait anxiety, self-mastery, and self-esteem): a reevaluation of the Life Orientation Test. Journal of Personality and Social Psychology 67, 1063-1078.

Schmid Y, Enzler F, Gasser P, Grouzmann E, Preller KH, Vollenweider FX, Brenneisen R, Muller F, Borgwardt S, Liechti ME (2014). Acute effects of lysergic acid diethylamide in healthy subjects. Biological Psychiatry 78, 544-553. 
Stokes PR, Mehta MA, Curran HV, Breen G, Grasby PM (2009). Can recreational doses of THC produce significant dopamine release in the human striatum? NeuroImage 48, 186-190.

Studerus E, Gamma A, Vollenweider FX (2010). Psychometric evaluation of the altered states of consciousness rating scale (OAV). PLoS ONE 5, e12412.

Studerus E, Kometer M, Hasler F, Vollenweider FX (2011). Acute, subacute and long-term subjective effects of psilocybin in healthy humans: a pooled analysis of experimental studies. Journal of Psychopharmacology 25, 1434-1452.

Tagliazucchi E, Carhart-Harris R, Leech R, Nutt D, Chialvo DR (2014). Enhanced repertoire of brain dynamical states during the psychedelic experience. Human Brain Mapping 35, 5442-5456.

Tellegen A, Atkinson G (1974). Openness to absorbing and self-altering experiences ("absorption"), a trait related to hypnotic susceptibility. Journal of Abnormal Psychology 83, 268-277.

Turecki G, Briere R, Dewar K, Antonetti T, Lesage AD, Seguin M, Chawky N, Vanier C, Alda M, Joober R, Benkelfat C, Rouleau GA (1999). Prediction of level of serotonin $2 \mathrm{~A}$ receptor binding by serotonin receptor $2 \mathrm{~A}$ genetic variation in postmortem brain samples from subjects who did or did not commit suicide. American Journal of Psychiatry 156, 1456-1458.

Umbricht D, Vollenweider FX, Schmid L, Grubel C, Skrabo A, Huber T, Koller R (2003). Effects of the 5- $\mathrm{HT}_{2 \mathrm{~A}}$ agonist psilocybin on mismatch negativity generation and
AX-continuous performance task: implications for the neuropharmacology of cognitive deficits in schizophrenia. Neuropsychopharmacology 28, 170-181.

Van Wel JH, Kuypers KP, Theunissen EL, Bosker WM, Bakker K, Ramaekers JG (2012). Effects of acute MDMA intoxication on mood and impulsivity: role of the $5-\mathrm{HT}_{2}$ and 5- $\mathrm{HT}_{1}$ receptors. PLOS ONE 7, e40187.

Vollenweider FX, Csomor PA, Knappe B, Geyer MA, Quednow BB (2007). The effects of the preferential 5- $\mathrm{HT}_{2 \mathrm{~A}}$ agonist psilocybin on prepulse inhibition of startle in healthy human volunteers depend on interstimulus interval. Neuropsychopharmacology 32, 1876-1887.

Vollenweider FX, Vollenweider-Scherpenhuyzen MF, Babler A, Vogel H, Hell D (1998). Psilocybin induces schizophrenia-like psychosis in humans via a serotonin-2 agonist action. Neuroreport 9, 3897-3902.

Weisstaub NV, Zhou M, Lira A, Lambe E, Gonzalez-Maeso J, Hornung JP, Sibille E, Underwood M, Itohara S, Dauer WT, Ansorge MS, Morelli E, Mann JJ, Toth M, Aghajanian G, Sealfon SC, Hen R, Gingrich JA (2006). Cortical 5- $\mathrm{HT}_{2 \mathrm{~A}}$ receptor signaling modulates anxiety-like behaviors in mice. Science 313, 536-540.

Williams GV, Rao SG, Goldman-Rakic PS (2002). The physiological role of $5-\mathrm{HT}_{2 \mathrm{~A}}$ receptors in working memory. Journal of Neuroscience 22, 2843-2854.

Zarate CA Jr., Singh JB, Carlson PJ, Brutsche NE, Ameli R, Luckenbaugh DA, Charney DS, Manji HK (2006). A randomized trial of an $\mathrm{N}$-methyl-D-aspartate antagonist in treatment-resistant major depression. Archives of General Psychiatry 63, 856-864. 